\title{
Kinesiophobia as a Problem in Adherence to Physical Activity Recommendations in Elderly Polish Patients with Coronary Artery Disease
}

This article was published in the following Dove Press journal: Patient Preference and Adherence

\author{
Andrzej Knapik (D) \\ Józefa Dąbek (iD ${ }^{2}$ \\ Anna Brzęk (D) ${ }^{3}$
}

'Department of Adapted Physical Activity and Sport, Chair of Physiotherapy, School of Health Sciences in Katowice, Medical University of Silesia in Katowice, Katowice, Poland; 2 Department of Cardiology, School of Health Sciences in Katowice, Medical University of Silesia in Katowice, Katowice, Poland; ${ }^{3}$ Department of Physiotherapy, Chair of Physiotherapy, School of Health Sciences in Katowice, Medical University of Silesia in Katowice, Katowice, Poland
Correspondence: Anna Brzęk

School of Health Sciences in Katowice, Department of Physiotherapy Chair of

Physiotherapy, Medical University of Silesia in Katowice, UI. Medyków 12,

Katowice 40-754, Poland

Tel +4832208872

Email aniabrzek@interia.pl
Introduction: The most commonly occurring diseases among the elderly people are cardiovascular system ones and among them the coronary artery disease (CAD). It is considered that the age and insufficient level of physical activity (PA) are the crucial risk factors of CAD. The key barrier which prevents elderly people from undertaking physical activity may be the fear of activity, called kinesiophobia.

Aim: The aim of this project was to examine the frequency of kinesiophobia among Polish elderly patients with CAD and its potential conditions: sex, age, CAD duration, other diseases and chosen socio-demographic variables.

Reference and methods: There have been 135 people examined: 59 women and 76 men in the $65-88$ age range (average $=71.88$ years, $\mathrm{SD}=4.82$ ). They were people diagnosed with stable CAD. The questionnaire form which was used collected information concerning the socio-demographical and physical activity data. And for kinesiophobia, there was Tampa Scale used, which is dedicated to examine cardiac patients - TSK heart.

Results: Over $76 \%$ of examined patients had a high level of kinesiophobia (TSK $>37 \mathrm{pt}$ ). Sex, age, BMI, CAD duration and the number of other diseases did not have any connection with neither PA nor TSK. Education was the only one, among the sociodemographic variables, which differentiated the kinesiophobia. Better educated people had a lower level of it.

Conclusion: Kinesiophobia is a common problem among the elderly people suffering from CAD. It is caused by a lack of physical activity which adversely predicts the progression of the disease. People with higher education are more rarely affected by kinesiophobia. CAD patients should be provided with knowledge and training concerning PA and there should be conditions created to enhance it.

Keywords: kinesiophobia, coronary artery disease, elderly patients, physical activity

\section{Introduction}

Among the range of other risk factors that can lead to coronary artery disease (CAD), age and insufficient level of physical activity (PA) are considered as the main ones. ${ }^{1}$ Age is an independent risk factor of CAD, which importance will be increasing in the social scale. ${ }^{2}$ The reason is the process of aging which has been observed in many developed countries. It refers to Polish society as well.

According to the parameters of the World Health Organization, the verge of demographic senescence in Poland was exceeded fifty years ago, and the elderly people's population currently equals $15.4 \%$ of the total. 
Within 25 years, the life expectancy in Poland has been expanded, 8 years for women and seven for men. That is why the prognosis predicts the further expansion of aging population. $^{3}$

In this context, the life expectancy in relatively good health, without disability involving daily basis activity limitations - Healthy Life Years - HLY, comes into prominence. What threatens the life expectancy in good health, is the prevalence rate and polipathology. It is a common phenomenon among the elderly people and it concerns approximately $20 \%$ to $98 \%$, depending on country and population. ${ }^{4}$ The most common afflictions occurring in old age are the cardiovascular ones and among them CAD. ${ }^{5}$ Despite the continuous development of modern diagnostic methods, interventional cardiology, new surgical techniques and more and more effective medicines, CAD is one of the main causes of health loss and death not only in Europe but all around the world. ${ }^{6,7}$

Optimal PA level is commonly considered as the main predictor of health. It refers not only to healthy people and the chronic patients but also to the stable patients with the circulatory system problems. ${ }^{8}$ The combination of treatment and the proper quantity of PA aims to provide relatively good biological and psychosocial functioning. In practice, it is difficult to achieve proper results. While patients generally follow the instructions for taking medications, their PA often does not meet the recommended guidelines. ${ }^{9,10}$ The reasons for it are complex. In case of elderly people, in addition to the natural limitations caused by age (a general decline in the performance of all systems), psychological factors have a significant influence, whose role in the etiology, course and treatment of cardiovascular diseases is very high. ${ }^{9}$ In addition to recognizing functional capabilities, knowledge about the causes of psychological limitations of activity may be the starting point for the implementation of intervention programs.

\section{Aim of the Work}

The aim of this work was to examine the problem of kinesiophobia, the fear of PA among the elderly people suffering from CAD. It was decided to examine the frequency of this problem and its potential determinants: age, gender and BMI. Also, selected sociodemographic determinants, which may be related to the studied problem, such as duration of CAD, the occurrence of other chronic diseases, the size of the place of residence, the way of running a household, education and self-assessment of physical activity have been taken into consideration.

\section{Ethics Approval}

The study was conducted according to the provisions of the Helsinki Convention, and also the Bioethics Committee of the Medical University of Silesia Katowice expressed its approval (Decision no.: KNW/0022/KBI/98/15). It is conformed to the Helsinki Declaration. All of the patients provided written informed consent prior to the study, including enrolment and data collection. All of the respondents provided written consent that they agree to take part in this study.

\section{Materials and Methods}

The study consisted of 153 people: 59 women (43.70\%) and 76 men $(56.30 \%)$. Age of respondents: $65-88$ years (average $=71.88$ years, $\mathrm{SD}=4.82$ ). The selection for the research was deliberate. The following criteria, for including in the study, were adopted: the subjects were people with stable CAD - reporting for follow-up consultations in scheduled mode, patients of the Cardiology Clinic in Katowice (southern Poland). The other selection criteria are: age of at least 65 years, voluntary participation in the study, relative motor independence in the field of mobility and self-service activities, and sufficient level of mental ability (contact with the patient, no cognitive disorders). Lack of those criteria excluded subjects from the study.

The research instrument which was used was an anonymous questionnaire, consisting of a metric part where the sociodemographic data of the respondents were collected (Table 1), closed questions regarding self-assessment of activity and physical activity of the respondents and the Polish version of Tampa Scale for Kinesiophobia for cardiac patients - TSK heart. ${ }^{11}$

In the metric part, the determinants that were taken into account were: gender, age, BMI, size of the residence (the division of the criteria was adapted to Polish conditions), the manner of running the household and the level of education. The questions regarding the prevalence rate of the respondents such as the duration of CAD from the diagnosis and the occurrence of other chronic diseases were included. Due to their diversity, the sum of other chronic diseases was taken into consideration for statistical analyses.

The self-evaluation of the respondents' activity was based on three variants:

1) I am fit - totally independent; 2) I am not fully fit but independent; 3) I am not fully fit, I often need help from other people.

Taking into account the selected criteria of the respondents, the age and prevalence rate, some of the questions 
Table I Descriptive Statistics of the Age, BMI, Duration of Cardiological Disease, Fitness, Activity and Kinesiophobia

\begin{tabular}{|c|c|c|c|c|c|c|}
\hline Variable & Mean & $\pm 95 \% \mathrm{Cl}$ & Median & Gender: $\mathbf{p}^{\mathbf{a}}$ & r- PAI ${ }^{\mathbf{b}}$ & $r-$ TSK $^{b}$ \\
\hline Age & 71.88 & $71.70-72.70$ & 71.00 & nss & nss & nss \\
\hline BMI & 28.61 & $27,77-29.46$ & 28.39 & nss & nss & nss \\
\hline Duration of cardiac disease & 12.10 & $10.11-14.10$ & 10.00 & nss & nss & nss \\
\hline The number (sum) of other chronic diseases & 2.05 & $1.76-2.34$ & 2.00 & $* *$ & -0.183 & 0.255 \\
\hline I. self-assessment of activity & 2.45 & $2.25-2.65$ & 2.00 & nss & 0.723 & -0.589 \\
\hline II. activity in free time & 2.59 & $2,37-2.80$ & 2.00 & nss & 0.772 & -0.633 \\
\hline III. inactivity in free time & 2.77 & $2.56-2.98$ & 3.00 & nss & 0.715 & -0.558 \\
\hline IV. walking & 2.61 & $2.44-2.79$ & 2.00 & nss & 0.681 & -0.588 \\
\hline V. time of walking & 2.60 & $2.36-2.84$ & 2.00 & nss & 0.763 & -0.595 \\
\hline PAI & 2.60 & $2.45-2.75$ & 2.40 & nss & & -0.800 \\
\hline TSK & 43.02 & $41.57-44.48$ & 43.00 & nss & -0.800 & \\
\hline
\end{tabular}

Notes: ${ }^{\mathrm{a} U}$ Mann-Whitney test; ${ }^{\mathrm{b}}$ Spearman correlation coefficient; ${ }^{* *} \mathrm{p}<0.01$.

Abbreviation: nss, not statistically significant.

from the Baecke physical activity questionnaire were used to estimate the level of activity. ${ }^{12}$ The PA examination included: self-assessment of activity (I), its intensity (II), inactivity (III) and walking - frequency (IV) and time (V).

The questions were closed and the answers to them were assigned to rank (points).

(I) I believe that my activity - compared to other people of my age is: 1) much smaller; 2) smaller; 3) the same; 4) bigger; 5) much bigger.

(II) In my spare time I do activities, exercise, play sports: 1) never; 2) rarely; 3) sometimes; 4) often; 5) very often.

(III) In my free time, I spend time sitting or lying: 1) very often; 2) often; 3) sometimes; 4) rarely; 5) never.

(IV) In my free time, I walk: 1) never; 2) rarely; 3) sometimes; 4) often; 5) very often.

(V) How many minutes a day do you walk (outside home - e.g. shopping, other activities): 1) less than 5; 2) 5-15 mins; 3) 15-30 mins; 4) 30-45 mins; 5) more than 45 mins.

The scoring of responses as well as the Physical Activity Index (PAI) which was calculated as the average number of these five questions - ranged from 1 to 5 .

The TSK used in this study concerns psychological attitudes towards physical effort (activity) and psychological responses to the effort that was made. ${ }^{13}$ In the presented study, the sum of points assigned to individual statements was used - the higher the sum of TSK points, the higher the level of kinesiophobia. The high level of kinesiophobia was considered in case TSK $>37$ points, which is the commonly accepted criterion. ${ }^{14}$

\section{Statistical Analysis}

Numerical and percentage statistics for qualitative variables were calculated. Descriptive statistics for quantitative variables were made: average, confidence intervals $\{ \pm 95 \% \mathrm{CI}\}$ and medians. Relations between variables were calculated using Spearman correlation. Nonparametric statistics were used for comparisons: chi ${ }^{2}$ test, U Mann-Whitney test and Kruskal-Wallis ANOVA. The assumed statistical significance level: $\mathrm{p}<0.05$.

\section{Results}

Initial analysis showed a good internal coherence for both PAI (alpha-Cronbach $=0.847$, half-life $=0.860$ ), as well as for TSK (alpha-Cronbach $=0.822$, half-life $=0.803$ ).

The analysis showed, which is natural, high correlation coefficients for particular aspects of PAI activity as well as high negative correlations with TSK. Age, BMI and prevalence rate had no relation with either PAI or TSK (Table 1).

The criterion of high level of kinesiophobia - TSK $>37$ points ${ }^{14}$ involved 103 people, which constituted $76.30 \%$ of all respondents. A comparison of the PA group with acceptable level of kinesiophobia (TSK <37) with the high level group (TSK > 37) showed differences regarding each activity aspect examined, as well as PAI: $p<0.001$ (Figure 1). In each case, the higher PA level was presented by people with a "normative" level of kinesiophobia.

Assuming a qualitative assessment of kinesiophobia as a grouping variable, the analyses did not show any differences regarding gender, age, duration of $\mathrm{CAD}$, or the number of other chronic diseases $(p>0.05)$. There were no differences in the examined sociodemographic variables except for education (Table 2). 


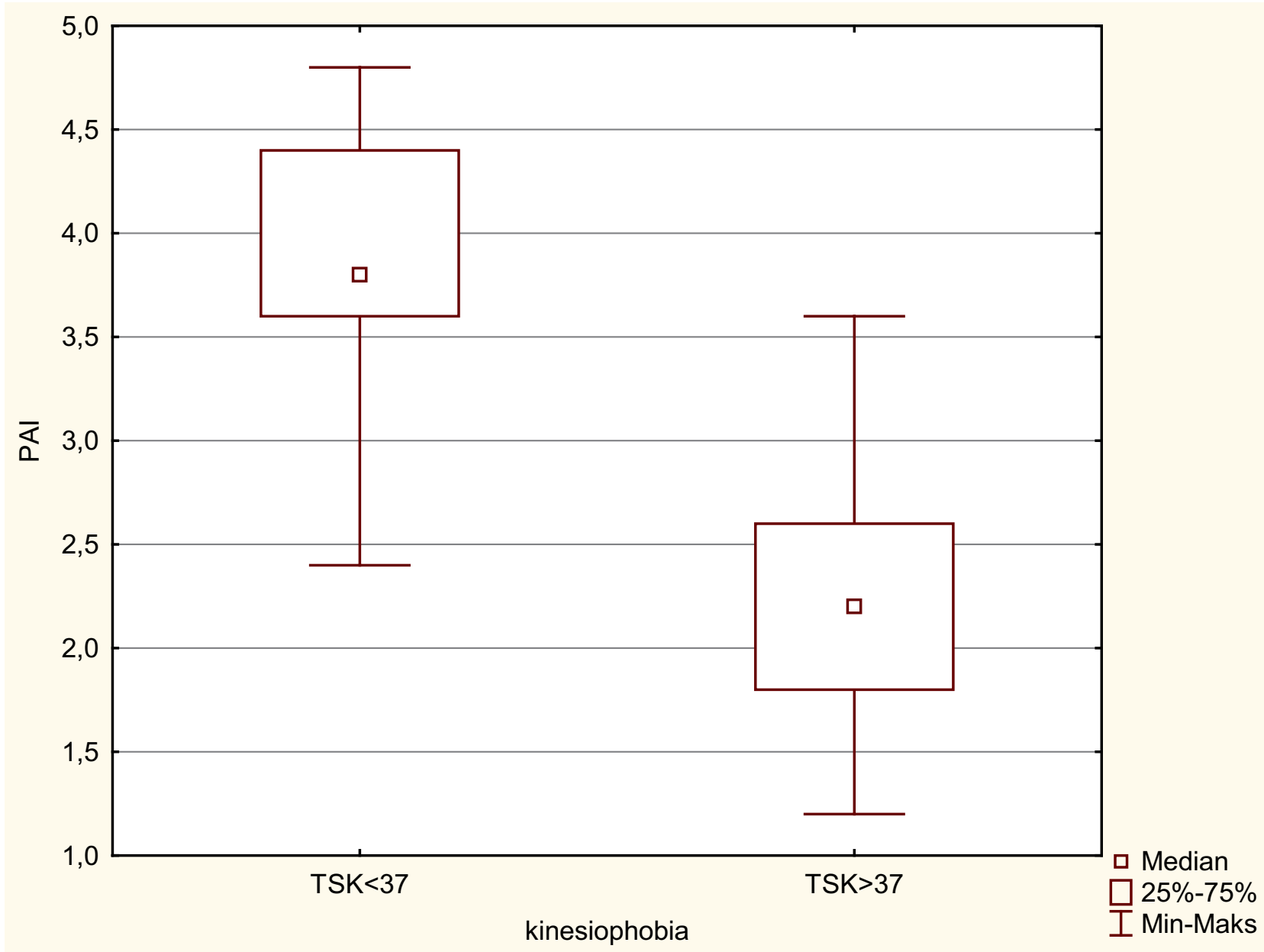

Figure I Qualitative assessment of kinesiophobia and activity.

Comparing the number of people in particular levels of education, links between higher education and the proportions of people can be noticed: TSK $<37$ points. - TSK $>37$ points (Figure 2).

\section{Discussion}

Barriers to physical activity, like activity itself, are a complex concept and can be understood differently. ${ }^{15}$ In the psychological aspect, the literature has dominated the biomedical perception of this problem, in which kinesiophobia is understood as fear of movement (activity) caused by illness or injury. ${ }^{16}$ The research instrument to study this problem - TKS, which was originally used among patients with back pain, is used to examine patients with other medical conditions. It also applies to cardiac patients. ${ }^{11,13,17}$ The reason for conducting these tests is the prevalence of inactivity among people who are ill. Their goal, in addition to cognitive aspects, is to develop or modify both rehabilitation programs and recommendations regarding the lifestyle for people who are ill.

The results of the presented study confirm the scale of this problem among patients with $\mathrm{CAD}$, according to the adopted criteria, over $76 \%$ of respondents had a high level of kinesiophobia. Its negative correlations with activity are very strong, which results in low activity rates (Table 1, Figure 1). The median of the basic activity index - daily walking time was within 5-15 mins, which significantly deviates from WHO, AHA and ESC recommendations. ${ }^{18-20}$ The presented data clearly indicate the dominating hypokinesia among the examined, which is the basis for the occurrence of many diseases, including cardiovascular diseases. In case of people suffering from $\mathrm{CAD}$, hypokinesis is not only a prognosis for the development of the disease and lowering the quality of life, but in the light of research - among elderly people with CAD significantly increases the mortality risk. $^{9,21}$ 
Table 2 Sociodemographic Variables, Kinesiophobia and Activity of the Respondents

\begin{tabular}{|c|c|c|c|c|c|c|c|}
\hline \multicolumn{2}{|l|}{ Variable } & \multirow[t]{2}{*}{$\mathbf{n}$} & \multirow[t]{2}{*}{$\%$} & \multicolumn{2}{|c|}{ Median } & \multicolumn{2}{|c|}{ TSK >37 } \\
\hline & & & & TSK & PAI & $\mathbf{c h i}^{2}$ & $\mathbf{p}$ \\
\hline The size of the place of residence & $\begin{array}{l}\text { The country } \\
\text { Town }<50 \text { tys. } \\
\text { Town } 50-100 \text { tys. } \\
\text { City }>100 \text { tys. }\end{array}$ & $\begin{array}{l}13 \\
3 \\
21 \\
98\end{array}$ & $\begin{array}{l}9.63 \\
2.22 \\
15.56 \\
72.59\end{array}$ & $\begin{array}{l}45.00 \\
47.00 \\
44.00 \\
42.00\end{array}$ & $\begin{array}{l}2.00 \\
3.00 \\
2.40 \\
2.40\end{array}$ & 0.1598 & NSS \\
\hline Household & $\begin{array}{l}\text { Alone } \\
\text { Only with the spouse } \\
\text { With family }\end{array}$ & $\begin{array}{l}32 \\
79 \\
24\end{array}$ & $\begin{array}{l}23.70 \\
58.52 \\
17.78\end{array}$ & $\begin{array}{l}45.00 \\
42.00 \\
45.50\end{array}$ & $\begin{array}{l}2.20 \\
2.60 \\
2.20\end{array}$ & 3.92 & NSS \\
\hline Education & $\begin{array}{l}\text { Elementary } \\
\text { Vocational } \\
\text { Secondary } \\
\text { Higher }\end{array}$ & $\begin{array}{l}17 \\
39 \\
55 \\
24\end{array}$ & $\begin{array}{l}12.59 \\
28.89 \\
40.74 \\
17.78\end{array}$ & $\begin{array}{l}45.00 \\
46.00 \\
43.00 \\
37.00\end{array}$ & $\begin{array}{l}2.20 \\
2.20 \\
2.40 \\
3.20\end{array}$ & 15.45 & $* *$ \\
\hline Self-assessment of physical fitness & $\begin{array}{l}\text { Fit, independent } \\
\text { Not fully fit, independent } \\
\text { Not fully fit, requires help }\end{array}$ & $\begin{array}{l}71 \\
49 \\
15\end{array}$ & $\begin{array}{l}52.59 \\
36.30 \\
11.11\end{array}$ & $\begin{array}{l}40.00 \\
44.00 \\
52.00\end{array}$ & $\begin{array}{l}2.60 \\
2.40 \\
1.80\end{array}$ & 5.26 & NSS \\
\hline
\end{tabular}

Note: ${ }^{* *} \mathrm{p}<0.01$.

Abbreviation: NSS, not statistically significant.

The study did not find any correlation between PA and TKS with age, duration of CAD, and the number of other chronic diseases. These results lead to the hypothesis that the disease is not the only cause of kinesiophobia and the associated passive movement. Verification of this hypothesis requires a broader, holistic view of the studied problem. ${ }^{22,23}$ First of all, physical inactivity, as a risk factor and as a behaviour accompanying CAD, can be considered in accordance with the theory of continuation. According to this theory, the behaviour of people is relatively stable, and continuing it for many years, is an adaptive strategy. ${ }^{24}$ It refers also to the problem of physical passivity. Secondly, what should be taken into consideration is the level of energy resources (vitality) of the respondents. Both the fear of discomfort in the form of pain or fatigue and their symptoms are common when it comes to elderly people. They may have both natural, agerelated background (decrease in the overall efficiency of many systems) and be associated with existing somatic diseases, or be connected with mood disorders. The feeling of general permanent fatigue is increasingly treated as a specific geriatric unit, ${ }^{25}$ and research shows that age is an important factor increasing its occurrence. ${ }^{26}$ The third element that should be taken into account is the environmental and social conditioning of inactivity. ${ }^{22,23}$ These include existing stereotypes of behaviour, economic status, and existing social networks. ${ }^{27}$ All of the previously mentioned conditions of kinesiophobia along with passive movement create a kind of servomechanism, mutually reinforcing one another. This thesis is confirmed by the results of Cohen-Mansfield et al research. The authors showed that the belief of being ill and poor activity are the main obstacles for PA of the elderly people. ${ }^{28}$ Thus, the mental sphere, and not the actual limitations associated with the disease, is often the cause of hypokinesia. This is also confirmed by the results of a multidimensional analysis carried out on a large population of older people by Meisner et al. According to the researchers, hypokinesia has a greater impact on functional limitations than the occurrence of chronic diseases. ${ }^{29}$

The only variable which showed statistical significance among the analyzed potential determinants of kinesiophobia was education (Table 2, Figure 2). Beneficial links between higher level of education and lower levels of kinesiophobia were also noted in other studies. ${ }^{13,22}$ On the other hand, research has shown that the elderly, better educated people present lower PA decrease with age, in comparison with less educated people. They are also better prepared to maintain regular physical activity after incidence and disability. This is interpreted as a consequence of more knowledge about the benefits of PA, a stronger sense of control, a greater sense of self-accuracy, healthier social network influences, better socio-economic status, and greater access to resources facilitating PA. 


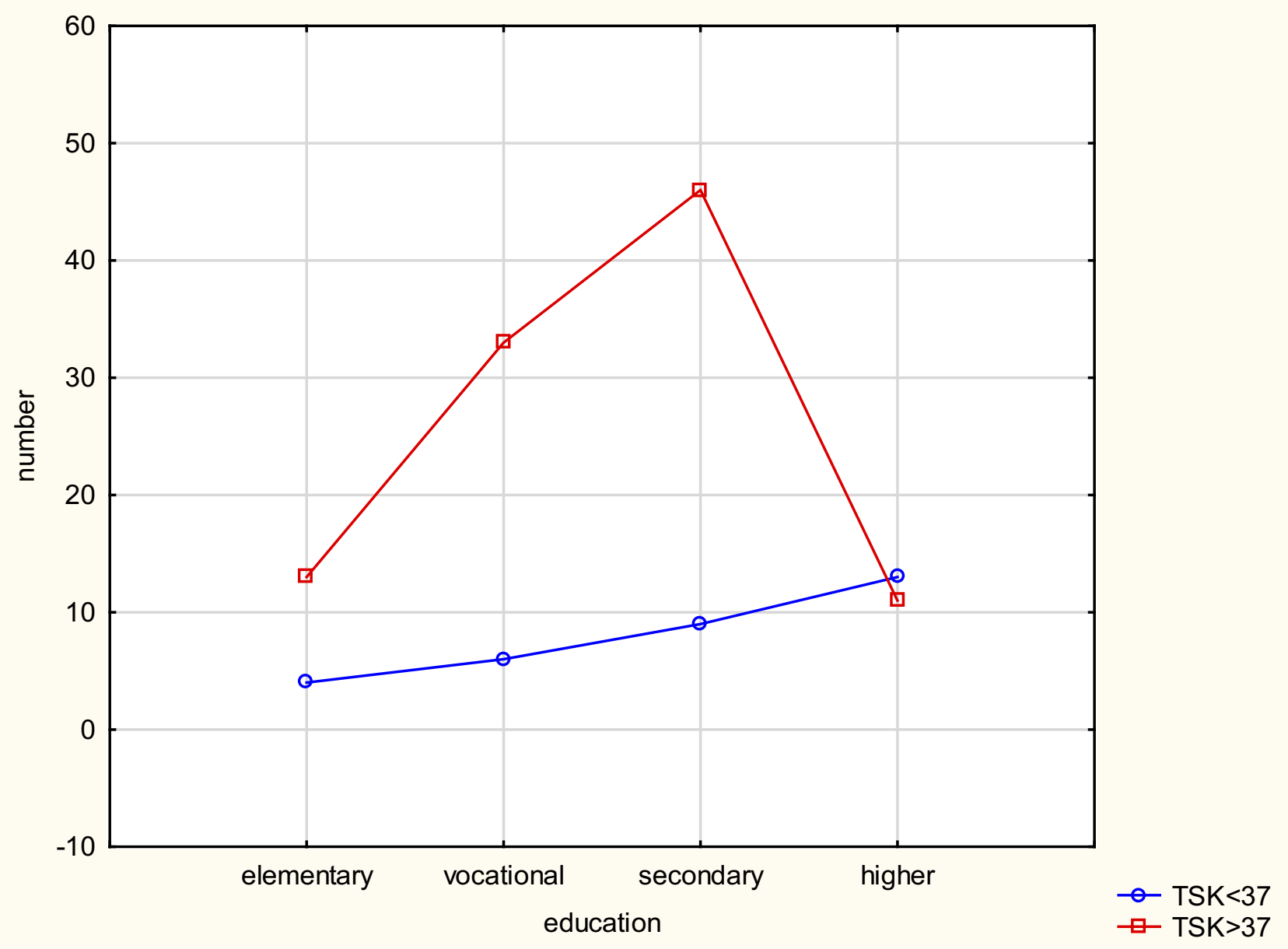

Figure 2 Qualitative assessment of kinesiophobia and education - interactions.

The presented results confirm the universality of the problem of kinesiophobia. Its diagnosis among patients with CAD is consistent with the risk reduction strategy, integrated with comprehensive cardiac rehabilitation. ${ }^{20}$ This rehabilitation effectively reduces total number of mortality, mortality from cardiovascular causes and the frequency of hospitalisations. Unfortunately, participation in rehabilitation is unsatisfactory, especially for older people who are in unfavorable socio-economical situation. Despite these limitations, inactive people should be encouraged to start a low-intensity exercise program after appropriate stratification of exercise risk. ${ }^{20}$ Even a small PA level provides benefits in terms of CAD risk, as compared to complete lack of activity. ${ }^{30}$

\section{Conclusion}

Kinesiophobia is a common problem among the elderly people suffering from CAD. It is the cause of physical inactivity which adversely predicts the progression of the disease. People with higher education are less likely to have kinesiophobia, comparing to the general population. Knowledge on the importance of physical activity in secondary prevention of CAD should be provided by doctors, nursing staff, physiotherapists, as well as organizations dealing with forms of social activation of seniors. It is important that the state and local governments support the creation of opportunities for older people to participate in active forms of recreation.

\section{Disclosure}

The authors report no conflicts of interest in this work.

\section{References}

1. Soares-Miranda L, Siscovick DS, Psaty BM, Longstreth WT, Mozaffarian D. Physical activity and risk of coronary heart disease and stroke in older adults: the cardiovascular health study. Circulation. 2016;133(2):147-155. doi:10.1161/CIRCULATIONAHA.115.018323

2. Dhingra R, Vasan RS. Age as a risk factor. Med Clin North Am. 2012;96(1):87-91. doi:10.1016/j.mcna.2011.11.003 
3. The Aging of the Polish Society and Its Effects. Thematic Studies OT601. Senate Chancellery, Warsaw 2011. [In Polish:] Starzenie Sie Spoleczeństwa Polskiego I Jego Skutki. Opracowania Tematyczne OT-601. Warszawa: Kancelaria Senatu; 2011. Available from: https://www.senat.gov.pl/gfx/senat/pl/senatopracowania/15/plik/ot601.pdf. Accessed September 18, 2018.

4. Vogeli C, Shields AE, Lee TA, et al. Multiple chronic conditions: prevalence, health consequences, and implications for quality, care management, and costs. J Gen Intern Med. 2007;22(supl.3):391-395. doi:10.1007/s11606-007-0322-1

5. Cierniak-Piotrowska M, Marciniak G, Stańczak J.. [Statistics of deaths and mortality due to cardiovascular diseases]. In: Strzelecki Z, Szymborski J, editors. Zachorowalność i umieralność na choroby układu krążenia a sytuacja demograficzna Polski. Warszawa: GUS; 2016:1-28. Polish

6. European Cardiovascular Disease Statistics. 2017. Available from: http://www.ehnheart.org/cvd-statistics.html. Accessed July 07, 2017.

7. WHO Cardiovascular disease. Available from: http://www.who.int/ cardiovascular_diseases/en/. Accessed July 07, 2017.

8. Löllgen H, Bachl N. Cardiovascular prevention and regular physical exercise: activity and training as the true "polypill". Herz. 2016;41 (8):664-670. doi:10.1007/s00059-016-4506-5

9. Piepoli MF, Conraads V, Corra U, et al. Exercise training in heart failure: from theory to practice. A consensus document of the Heart Failure Association and the European Association for Cardiovascular Prevention and Rehabilitation. Eur J Heart Fail. 2011;13 (4):347-357. doi:10.1093/eurjhf/hfr017

10. Campkin LM, Boyd JM, Campbell DJT. Coronary artery disease patient perspectives on exercise participation. JCRP. 2017;37 (5):305-314. doi:10.1097/HCR.0000000000000195

11. Bäck M, Cider A, Herlitz J, Lundberg M, Jannson B. The impact on kinesiophobia (fear of movement) by clinical variables for patients with coronary artery disease. Int J Cardiol. 2013;167(2):391-397. doi:10.1016/j.ijcard.2011.12.107

12. Baecke JA, Burema J, Frijters JE. A short questionnaire for the measurement of habitual physical activity in epidemiological studies. Am J Clin Nutr. 1982;36:936-942. doi:10.1093/ajcn/36.5.936

13. Brunetti ND, Guerra A, Ieva R, et al. Scared for the scar: fearsome impact of acute cardiovascular disease on perceived kinesiophobia (fear of movement). Clin Cardiol. 2017;40:480-484. doi:10.1002/clc.22682

14. Vlaeyen JW, Kole-Snijders AM, Boeren RG, van Eek H. Fear of movement/(re)injury in chronic low back pain and its relation to behavioral performance. Pain. 1995;62:363-372. doi:10.1016/03043959(94)00279-N

15. Bethancourt HJ, Rosenberg DE, Beatty T, Arterburn DE. Barriers to and facilitators of physical activity program use among older adults. Clin Med Res. 2014;12(1-2):10-20. doi:10.3121/cmr.2013.1171

16. Kori SH, Miller RP, Todd DD. Kinesiophobia: a new view of chronic pain behavior. Pain Manag. 1990;3:35-43.

17. Acar S, Savci S, Keskinoğlu P, et al. Tampa Scale of Kinesiophobia for Heart Turkish Version Study: cross-cultural adaptation, exploratory factor analysis, and reliability. J Pain Res. 2016;9:445-451. doi:10.2147/JPR.S105766

Patient Preference and Adherence

\section{Publish your work in this journal}

Patient Preference and Adherence is an international, peer-reviewed, open access journal that focusing on the growing importance of patient preference and adherence throughout the therapeutic continuum. Patient satisfaction, acceptability, quality of life, compliance, persistence and their role in developing new therapeutic modalities and compounds to optimize clinical outcomes for existing disease
18. WHO. Physical Activity and Older Adults. Available from: https:// www.who.int/dietphysicalactivity/factsheet_olderadults/en/. Accessed March 22, 2019.

19. Nelson ME, Rejeski WJ, Blair SN, et al. Physical activity and public health in older adults: recommendation from the American College of Sports Medicine and the American Heart Association. Circulation. 2007;116(9):1094-1105. doi:10.1161/CIRCULATIONAHA.107.185650

20. Perk J, De Backer G, Gohlke H, et al. Guidelines on cardiovascular disease prevention in clinical practice (version 2012): the Fifth Joint Task Force of the European Society of Cardiology and Other Societies on Cardiovascular Disease Prevention in Clinical Practice (constituted by representatives of nine societies and by invited experts). Eur Heart J. 2012;33:1635-1701. doi:10.1093/eurheartj/ ehs092

21. Janssen I, Jolliffe CJ. Influence of physical activity on mortality in elderly with coronary artery disease. MSSE. 2006;38(3):418. doi:10.1249/01.mss.0000191185.58467.be

22. Knapik A, Saulicz E, Rottermund J, Saulicz M, Myśliwiec A. Successful Aging - the role of physical activity and its barriers in women of advanced age. In: Moravcikova D, Vasko M, editors. Family-Health-Disease. Zlin: Univerzita Tomase Bati ve Zline; 2014:13-22.

23. Knapik A, Rottermund J, Saulicz E, Linek P, WarmuzWancisiewicz A, Myśliwiec A. Successful ageing: the role of physical activity and its barriers in Polish men of advanced age. CEJSSM. 2017;18(2):67-75.

24. Atchley RC. A continuity theory of normal aging. Gerontologist. 1989;29(2):183-190. doi:10.1093/geront/29.2.183

25. Liao S, Ferrell BA. Fatigue in an older population. J Am Geriatr Soc. 2000;48(4):426-430. doi:10.1111/jgs.2000.48.issue-4

26. Wijeratne C, Hickie I, Brodaty $H$. The characteristics of fatigue in an older primary care sample. J Psychosom Res. 2007;62(2):153-158. doi:10.1016/j.jpsychores.2006.09.011

27. Shelton RC, McNeill LH, Puleo E, et al. The association between social factors and physical activity among low-income adults living in public housing. Am J Public Health. 2011;101(11):2102-2110. doi:10.2105/AJPH.2010.196030

28. Cohen-Mansfield J, Marx MS, Guralnik JM. Motivators and barriers to exercise in an older community-dwelling population. JAPA. 2003;11(2):242-253. doi:10.1123/japa.11.2.242

29. Meisner BA, Dogra S, Logan AJ, Baker J, Weir PL. Do or decline?: comparing the effects of physical inactivity on biopsychosocial components of successful aging. $J$ Health Psychol. 2010;15(5):688-696. doi:10.1177/1359105310368184

30. Lachman S, Boekholdt SM, Luben RN, et al. Impact of physical activity on the risk of cardiovascular disease in middle-aged and older adults: EPIC Norfolk prospective population study. Eur J Prev Cardiol. 2018;25(2):200-208. doi:10.1177/204748731773 7628

states are major areas of interest for the journal. This journal has been accepted for indexing on PubMed Central. The manuscript management system is completely online and includes a very quick and fair peer-review system, which is all easy to use. Visit http:// www.dovepress.com/testimonials.php to read real quotes from published authors. 